\title{
Clostridial pathogenicity in experimental necrotising enterocolitis in gnotobiotic quails and protective role of bifidobacteria
}

\author{
M. J. BUTEL, N. ROLAND*, A. HIBERT, F. POPOT*, A. FAVRE†, A. C. TESSEDRE, \\ M. BENSAADA†, A. RIMBAULT and O. SZYLIT*
}

Faculté des Sciences Pharmaceutiques et Biologiques, Laboratoire de Microbiologie, Unité Microbiologie Anaérobie, Université René Descartes, Paris, *Unité d'Ecologie et Physiologie du Système Digestif, Equipe Métabolites Bactériens et Santé, Institut National de la Recherche Agronomique, Jouy-en-Josas and $\uparrow$ Service de Médecine Néonatale, Centre de Pédiatrie Gatien de Clocheville, Tours, France

\begin{abstract}
The pathogenesis of neonatal necrotising enterocolitis (NEC) remains unclear. Gnotobiotic quails fed a lactose diet have been used to investigate the role of clostridial strains originating from faecal specimens of neonates through the intestinal lesions, the changes in microflora balance and the production of bacterial metabolites, i.e., shortchain fatty acids and hydrogen. Bifidobacteria are thought to exert various beneficial effects on host health, including interaction with the colonic microflora. Therefore, it was hypothesised that a protective role could be exercised through bifidobacterial colonisation. A Clostridium butyricum strain (CB 155-3) and a whole faecal flora including three clostridial species ( $C$. butyricum, $C$. perfringens, $C$. difficile), each from premature infants suffering from NEC, caused caecal lesions in quails similar to those observed in man, i.e., thickening of the caecal wall with gas cysts, haemorrhagic ulceration and necrotic areas. Conversely, a whole faecal flora including bifidobacteria (identified as Bifidobacterium pseudo-catenulatum) and no clostridia, isolated from a healthy premature infant, was unable to produce NEC-like lesions. When the two clostridial groups were associated with a Bifidobacterium strain (B. infantis-longum, CUETM 89-215, isolated from a healthy infant), bifidobacterial colonisation suppressed all pathological lesions. This study is the first demonstration of a protective role for bifidobacteria against NEC via the inhibition of growth of $C$. butyricum or the disappearance of $C$. perfringens. $C$. difficile was not found to be responsible for the aetiology of the caecal lesions in quails. The main effect of bifidobacteria on lactose fermentation was either a dramatic decrease or a disappearance of butyric acid. The protective role was not associated with changes in $\mathrm{H}_{2}$ production. Therefore, a new step between colonic colonisation and its relevance to NEC is thought to involve the fermentation of unabsorbed lactose into butyric acid at the onset of the disease.
\end{abstract}

\section{Introduction}

Bifidobacteria are dominant in the faeces of full term neonates fed breast milk and this feature is associated with a low colonisation by Enterobacteriaceae, enterococci and anaerobic bacteria such as members of genera Bacteroides and Clostridium [1-4]. Various bifidobacteria are reported to have an inhibitory effect on different bacterial pathogens both in vitro $[5,6]$ and

Received 1 June 1997; revised version accepted 29 Aug. 1997.

Corresponding author: Dr M. J. Butel. in a rat model [7] involving bifidobacteria and $C$. perfringens, Escherichia coli and, to a lesser extent, several other enteropathogens. Moreover, bifidobacteria are considered to exert various biological activities related to host health [7].

Colonisation by bifidobacteria is delayed in premature infants as compared with full-term infants [8-10]. Necrotising enterocolitis (NEC), which predominantly affects premature infants, is a very severe illness characterised by abdominal distension, gastrointestinal bleeding, mucosal ulcerations and intestinal pneumatosis [11]. The pathogenesis remains unclear and several factors are involved, including injury to the 
intestinal mucosa, enteral feeding and colonisation by enteric bacteria [11]. The bacteria most often associated with the disease are Klebsiella spp. [12], E. coli [13] and several clostridia [14-18]. Among clostridia, the most commonly isolated species are $C$. butyricum [19-22] and $C$. perfringens [14, 16, 17].

Studies in gnotobiotic animals have helped to define a role for $C$. butyricum in the onset of NEC. Gnotobiotic chickens [23] and quails [24] colonised with $C$. butyricum strains displayed NEC-like lesions in the caeca when fed a lactose diet. Like premature babies, birds exhibit a low endogenous lactase activity and their caeca present a physiological stasis favouring overgrowth with lactose-fermenting bacteria.

Enhanced colonic bacterial fermentation and its possible relevance to NEC have been reviewed [2527]. According to Clarks et al. [27] the rapid onset of lactose fermentation and the immediate production of organic acids may be responsible for the onset of NEC. Hydrogen $\left(\mathrm{H}_{2}\right)$-producing bacteria are responsible for $\mathrm{H}_{2}$ found in the NEC gas cysts [28]. Among bacterial metabolites, short-chain fatty acids (SCFAs) excretion reflects intracolonic fermentation of carbohydrates and proteins which are involved in different aspects of colonic functions and interfere with intraluminal events, absorption and mucosal metabolism [29].

NEC is 6-to-10 times less common in babies fed only breast milk than in those fed only formula, which suggests a protective role for breast milk [30]. Fresh human milk has been shown to promote the growth of bifidobacteria [1, 3, 9]. As these bacteria are known to change the proportion of organic acids such as acetic and lactic acids [5], it was hypothesised that the protective role can be exerted through bifidobacterial colonisation.

The aim of the study was to use whole faecal flora originating from premature human infants to determine whether clostridia were involved in NEC and if colonisation with bifidobacteria results in a reduction of the prevalence or severity of the disease, or both. This was investigated in gnotobiotic quails by studying the incidence of intestinal lesions, the changes in the microflora balance and the production of bacterial metabolites.

\section{Materials and methods}

\section{Bacterial strains and flora}

Three different microflora were investigated: one $C$. butyricum strain (strain CB155-3 isolated from a premature human infant suffering from NEC and used in a previous study [24]) and two faecal flora which came from premature dizygotic twins, born at a gestational age of 33 weeks at the Centre of Pédiatrie Gatien de Clocheville, France. No antibiotic treatment was given at birth and enteral feeding started at day 2 with breast milk. One twin had no digestive problem whereas the other developed NEC a few hours after stool collection with bloody and mucous stools, so that the corresponding faecal flora were referred to as normal flora and NEC flora, respectively. Stools were collected on day 4 in glycerol-brain-heart broth in an anaerobic bag (Anaerocult Merck) and immediately frozen $\left(-80^{\circ} \mathrm{C}\right)$. The quantitative studies of the aerobic and anaerobic faecal flora were performed by the techniques described below. Bifidobacterium infantislongum (abbreviated as B.inf.; strain CUETM 89-215, collection de l'Unité d'Ecotoxicologie Médicale, INRA, Villeneuve d'Ascq, France) was isolated from the stool of a healthy premature infant.

\section{Maintenance and inoculation of quails}

Germ-free quails (Coturnix, coturnix subsp. japonica) were obtained by the method of Reynier and Sackteder [31] with the modifications described by Bousseboua et al. [24]. Six groups of 2-week-old germ-free quails were transferred to the various experimental isolators and colonised with known flora (gnotobiotic quails, Table 1). Group A was associated with $C$. butyricum CB155-3 alone (monobiotic quails) and group B was associated with the NEC flora (polybiotic quails). Group $\mathrm{C}$ was associated with the normal flora (polybiotic quails). To investigate the influence of $B$. infantis-longum, two other groups were associated with either $C$. butyricum plus $B$. infantislongum (group $\mathrm{A}+B$. inf., dibiotic quails) or the NEC flora plus $B$. infantis-longum (group $\mathrm{B}+B$. inf.,

Table 1. Characteristics of six groups of germ-free quails inoculated with various flora

\begin{tabular}{|c|c|c|c|c|}
\hline \multirow{2}{*}{$\begin{array}{l}\text { Group of } \\
\text { quails }\end{array}$} & \multirow{2}{*}{$\begin{array}{l}\text { Number } \\
\text { of quails }\end{array}$} & \multicolumn{2}{|c|}{ Inoculum } & \multirow{2}{*}{$\begin{array}{l}\text { Status of } \\
\text { gnotobiotic quails }\end{array}$} \\
\hline & & Infant flora & Strain added & \\
\hline A & 11 & C. butyricum ${ }^{*}$ & $\cdots$ & Monobiotic \\
\hline B & 9 & NEC flora & $\cdots$ & Polybiotic \\
\hline $\mathrm{C}$ & 8 & Normal flora & $\cdots$ & Polybiotic \\
\hline$A+B$. infantis-longum & 11 & C. butyricum* & B. infantis-longum ${ }^{\dagger}$ & Dibiotic \\
\hline $\mathrm{B}+B$. infantis-longum & 8 & NEC flora & B. infantis-longum ${ }^{\dagger}$ & Polybiotic \\
\hline $\mathrm{C}+C$. butyricum & 12 & Normal flora & C. butyricum ${ }^{*}$ & Polybiotic \\
\hline
\end{tabular}

*Strain CB 155-3.

†'Strain CUETM 89-215. 
polybiotic quails). To investigate the influence of clostridia, one group was associated with the normal flora plus C. butyricum CB 155-3 (group C $+C$. but., polybiotic quails). The germ-free status of quails was checked before each experiment. Quails were inoculated orally with cultures containing $10^{8}$ viable cells of $C$. butyricum or B. infantis-longum $/ \mathrm{ml}$ or a 10 -fold dilution of the faecal flora (volume $100 \mu \mathrm{l}$ ), or both. Bacterial establishment was checked in fresh droppings at weekly intervals.

\section{Diets}

Quails were fed an experimental semi-synthetic diet [24] containing lactose $(6-8 \% \mathrm{w} / \mathrm{w})$ to mimic the proportion of lactose in milk. The diet was sterilised by $\gamma$-irradiation at $40 \mathrm{kGy}$.

\section{Sampling, bacterial counts, and biochemical determinations}

At the end of the experiments, the quails were transferred to a respiratory chamber and hydrogen production was measured with a Quintron apparatus [32]. Quails were then killed at between 2 and 3 weeks for group A and on day 21 for the other groups. Caeca were collected immediately after death and the contents were removed for $\mathrm{pH}$ measurement, and bacteriological and biochemical determinations. The weight of the caecal wall was expressed as the caecal wall weight/ body weight ratio. Caeca were examined macroscopically and categorised as normal $(\mathrm{N})$, thickening $(\mathrm{T})$, pneumatosis (P) and haemorrhagic contents $(\mathrm{H})$. As there is a good correlation between macroscopic and microscopic observations [24], histological aspects were checked on only two healthy animals and half of the sick animals. Samples were fixed in a Bouin solution, embedded in paraffin, serially sectioned and stained with haematoxylin and eosin.

The caecal contents were weighed and homogenised in a peptone liquid medium and repeatedly diluted in 100 -fold steps from $10^{2}$ to $10^{6}$ for bacterial counts. The dilutions were spread on several agar media with the Spiral System (AES Laboratoire, F-35270 Combourg, France). The count threshold was $10^{4} \mathrm{cfu} / \mathrm{g}$ of fresh faeces. When counts of clostridia were below this threshold, undiluted samples were examined and counts listed as $<4.0$. Aerobic cultures were performed on Drigalski agar (Diagnostics Pasteur) for enterobacteria. Enterococcosel (bioMérieux) for enterococci and Chapman 110 Agar (Merck) for staphylococci; all were incubated at $37^{\circ} \mathrm{C}$. For anaerobic bacteria, the dilutions were plated on different media, i.e., cysteine $(160 \mathrm{mg} / \mathrm{L})$ Columbia agar base supplemented with sheep blood $5 \%$ and neomycin $100 \mathrm{mg} / \mathrm{L}$ for total anaerobes; whole milk $5 \%$, colistin $10 \mathrm{mg} / \mathrm{L}$ and neutral red $40 \mathrm{mg} / \mathrm{L}$ for clostridia [33]; $C$. difficile supplement (bioMérieux) for $C$. difficile, and trimethoprim $16 \mathrm{mg} / \mathrm{L}$. D-cycloserine $10 \mathrm{mg} / \mathrm{L}$ and polymyxin B sulphate $20 \mathrm{mg} / \mathrm{L}$ for C. butyricum [34]. For bifidobacteria, Wilkins Chalgren agar base containing D-glucose $10 \mathrm{~g} / \mathrm{L}$, kanamycin $7.5 \mathrm{mg} / \mathrm{L}$, Lcysteine $0.5 \mathrm{~g} / \mathrm{L}$ and Tween $800.5 \% \mathrm{v} / \mathrm{v}$ was used. Plates were incubated at $37^{\circ} \mathrm{C}$ in anaerobic jars in an anaerobic gas phase $\left(\mathrm{H}_{2}: \mathrm{CO}_{2}, 95: 5 \mathrm{v} / \mathrm{v}\right)$. Aerobic cultures were examined on days 1 and 2 and anaerobic ones on days 2 and 5. Anaerobic bacteria were identified according to Holdeman et al. [35]. Bacterial numbers were expressed as the $\log _{10} \mathrm{cfu} / \mathrm{g}$ of faeces or caecal content.

SCFA concentrations were determined by gas chromatography [36]. A saturated mercuric chloride solution $(10 \% \mathrm{v} / \mathrm{v})$ was added to the caecal content samples which were then frozen. Before the analysis, samples were thawed and centrifuged and the supernates were deproteinised with phosphotungstic acid (saturated solution $0.4 \mathrm{ml} / \mathrm{g}$ of contents) for $16 \mathrm{~h}$ at $0^{\circ} \mathrm{C}$.

\section{Statistical analysis}

Data presented as the mean and SD were evaluated statistically by Student's $t$ test.

\section{Results}

\section{Composition of the two newborn faecal flora and} their establishment in quails

Differences were apparent between the normal flora inoculum for group $C$ and the NEC flora inoculum for group B (Table 2). Both contained enterococci and Proteus mirabilis, but E. coli was present only in the normal flora. The major differences observed were the occurrence in the NEC flora of three different Clostridium species: C. butyricum at high level and $C$. difficile and $C$. perfringens at low levels. In the normal flora, clostridia were not detected and a high level of bifidobacteria was found. Bifidobacteria were identified as $B$. catenulatum or $B$. pseudocatenulatum on the basis of phenotypic characters (biochemical and enzymatic characters; bioMérieux API, F-69280 Marcy l'Etoile, France) with the numerical identification system developed by F. Gavini (personal communication) and further listed as B. pseudo-catenulatum.

The implantation of the inoculum was checked in the faeces of the quails on day 3 after inoculation. The faecal flora showed some modifications compared with the inoculum (data not shown). In group $\mathrm{B}, C$. butyricum, the dominant Clostridium sp. in the faeces from the premature sick twin, was no longer detected 1 week after inoculation, although $C$. perfringens became established at a relatively high level $\left(\log _{10}\right.$ 5.0-7.0) in the quails, by 2 weeks after inoculation. In group $\mathrm{C}, P$. mirabilis and enterococci which were at low levels in the healthy twin faeces were established at high levels (c. $\log _{10} 8.0$ and 7.0 , respectively) 


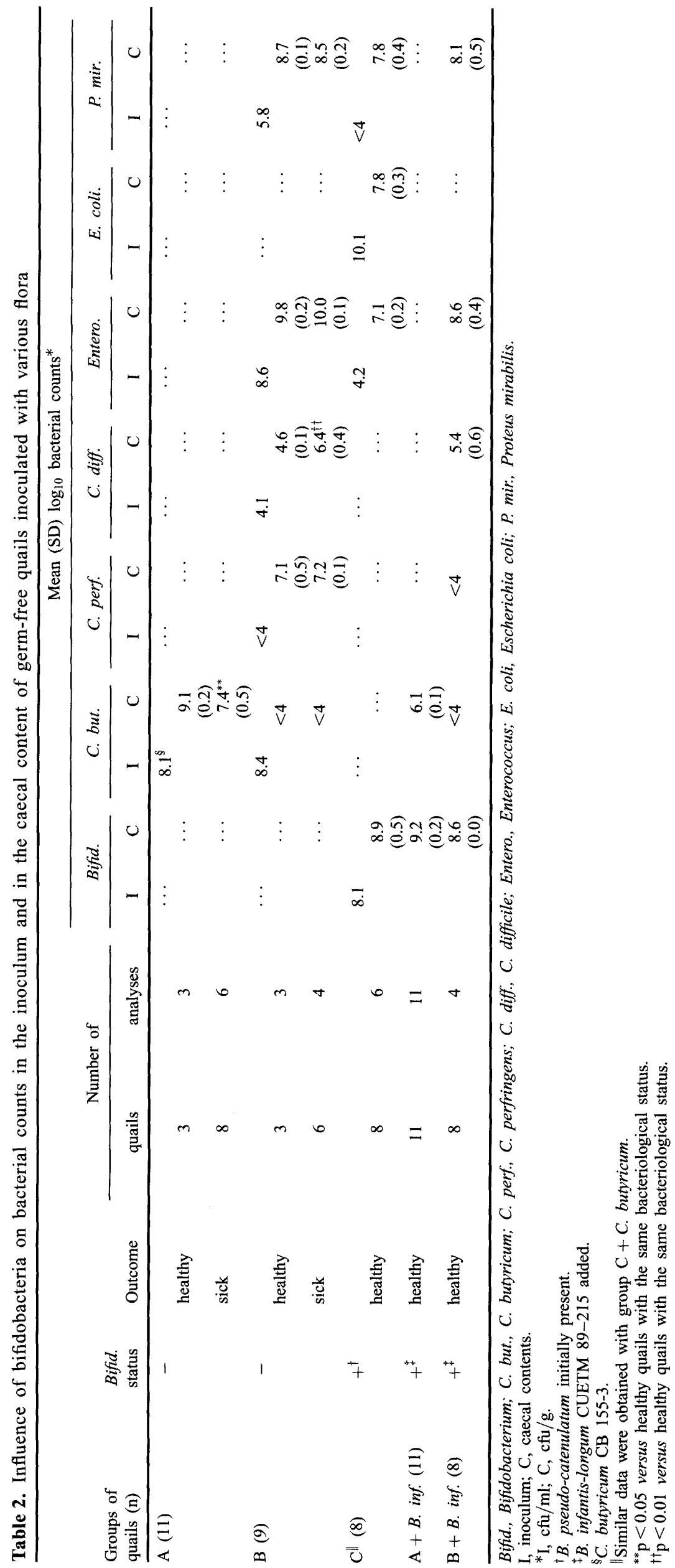


whereas a decrease was observed in $E$. coli counts (from $\log _{10} 10.1$ to $c$. 8.0). Other bacteria isolated from both twin faeces were found at a similar level in quails of groups B and $\mathrm{C}$.

\section{In-vitro SCFA formation by Clostridium spp.}

The SCFA profile comprised acetic, butyric and propionic acids (the latter in small amounts) for $C$. perfringens; acetic and butyric acids for the isolates of C. butyricum; acetic, butyric, isocaproic, and, in small amounts, propionic, isobutyric, isovaleric and valeric acids for $C$. difficile. For the Bifidobacterium strains, only acetic acid was detected.

\section{Caecal changes in quails inoculated with the non- bifidobacterial flora (groups $A$ and $B$ )}

Caecal bacterial counts. In group A, C. butyricum was established at a high level (Table 2). A significant decrease in this population was observed when lesions were found as compared with healthy animals. In group $\mathrm{B}, C$. butyricum was not detected and $C$. perfringens appeared at the same level in both healthy and sick animals (c. $\log _{10} 7.0$ ). The only difference was the significant increase in the $C$. difficile counts in quails displaying intestinal lesions ( $\log _{10} 6.4$ versus 4.6$)$.

Occurrence of caecal lesions. In group A, caecal lesions were observed in eight of the 11 quails (Table 3 ). The caecal wall weight was significantly enhanced in the eight sick animals as compared with the three healthy ones. In group B, caecal lesions were observed in six of the nine quails and the occurrence of lesions led to a significant increase in the caecal wall weight. Moreover, the caecal wall in polybiotic quails appeared significantly thicker than in monobiotic quails, both in healthy and sick animals. Thickening was associated with haemorrhagic contents in six cases and pneumatosis in five cases.

Bacterial fermentation metabolites. Total caecal SCFA concentrations were about six times higher in group B than in group A, but in both groups, the caecal lesions were not associated with a modification in the concentrations (Table 4). Acetic, butyric and isobutyric acids were the three SCFAs detected in group A, whereas the profiles were more complex in group B, as propionate, valerate and isovalerate and caproate were also detected.

Caecal $\mathrm{pH}$ was not different in groups $\mathrm{A}$ and $\mathrm{B}$ in the healthy quails. Caecal lesions in group $\mathrm{A}$ were associated with a $\mathrm{pH}$ increase in comparison to group B.

\section{Caecal changes in quails inoculated with Bifidobacterium-containing flora}

Caecal bacterial counts. The Bifidobacterium strain was established at a high level in quails (c. $\log _{10} 9.0$ ) when it was added in groups A and B or initially present in group $\mathrm{C}$ (Table 2). The colonisation with bifidobacteria led to a fall of $C$. butyricum numbers in quails of groups $\mathrm{A}+B$. inf. and of $C$. perfringens in quails of group $\mathrm{B}+B$. inf. $C$. difficile level did not significantly differ between groups $\mathrm{B}$ and $\mathrm{B}+B$. inf. when compared to either healthy or sick animals. The other population levels (enterobacteria, enterococci) were not modified.

In group $\mathrm{C}+C$. but. the levels of the strains of group $\mathrm{C}$ were the same as was found in group $\mathrm{C}$, and $C$. butyricum failed to colonise the quails (data not shown in the table).

Occurrence of caecal lesions. No caecal lesions were detected 21 days after inoculation whatever the group studied (Table 3). The caecal wall weights did not significantly differ between the four groups (mean value $=3.5$ ).

Bacterial fermentation metabolites. With the exception of sick animals of group A, there were no differences in caecal $\mathrm{pH}$ between groups with and without bifidobacteria (Table 4). However, total SCFA concentrations and profiles were strongly affected. With group $\mathrm{A}+B$. inf., the total SCFA concentration doubled as compared with group $\mathrm{A}$, but only acetic acid was detected. With group $\mathrm{B}+B$. inf., the total SCFAs concentration was decreased by a factor of 2 compared with group $\mathrm{B}$ and proportions of butyric acid and SCFAs of protein origin decreased. Consequently, in

Table 3. Influence of bifidobacteria on caecal changes in germ-free quails inoculated with various flora

\begin{tabular}{|c|c|c|c|c|c|c|c|c|c|c|c|c|}
\hline \multirow{2}{*}{$\begin{array}{l}\text { Group of } \\
\text { quails (n) }\end{array}$} & \multirow{2}{*}{$\begin{array}{l}\text { Bifid. } \\
\text { status }\end{array}$} & \multirow[b]{2}{*}{ Outcome } & \multirow{2}{*}{$\begin{array}{l}\text { Number } \\
\text { of quails }\end{array}$} & \multirow{2}{*}{$\begin{array}{l}\text { Mean (SEM) } \\
\text { caecal wall wt/ } \\
\text { body wt }\left(10^{3}\right)\end{array}$} & \multicolumn{8}{|c|}{ Number of quails with macroscopic observation } \\
\hline & & & & & $\mathrm{N}$ & $\mathrm{T}$ & $\mathbf{H}$ & $\mathbf{P}$ & $\mathrm{T}+\mathrm{H}$ & $\mathbf{T}+\mathbf{P}$ & $\mathrm{P}+\mathrm{H}$ & $\mathrm{T}+\mathrm{P}+\mathrm{H}$ \\
\hline \multirow[t]{2}{*}{$A(11)$} & - & healthy & 3 & $2.97(0.09)$ & 3 & & & & & & & \\
\hline & & sick & 8 & $4.05(0.18)^{*}$ & 0 & 2 & 0 & 0 & 4 & 2 & 0 & 0 \\
\hline \multirow[t]{2}{*}{ B (9) } & - & healthy & 3 & $3.88(0.11)$ & 3 & & & & & & & \\
\hline & & sick & 6 & $4.99(0.42)^{*}$ & 0 & 0 & 2 & 1 & 0 & 0 & 1 & 2 \\
\hline$C(8)$ & $++^{\dagger}$ & healthy & 8 & $3.61(0.18)$ & 8 & & & & & & & \\
\hline$A+B$ inf. (11) & $+^{*}$ & healthy & 11 & $3.24(0.16)$ & 11 & & & & & & & \\
\hline $\mathrm{B}+B$.inf $(8)$ & $+^{\ddagger}$ & healthy & 8 & $3.65(0.28)$ & 8 & & & & & & & \\
\hline
\end{tabular}

$\mathrm{N}$, normal; $\mathrm{T}$, thickening; $\mathrm{H}$, haemorrhagic; $\mathrm{P}$, pneumatosis.

${ }^{*} \mathrm{p}<0.05$ versus healthy quails with the same bacteriological status.

${ }^{+}$, See footnote to Table 2 . 
both cases, B. infantis-longum had a more important role in bacterial metabolism than in acidification.

With group $\mathrm{C}$, the caecal $\mathrm{pH}$ and the SCFA concentration were close to the data obtained with group $\mathrm{B}+B$. inf. The main differences concerned the SCFA profile, with a higher proportion of acetic acid $(93.7 \%)$ and very low proportions of SCFAs originating from proteolytic or aminoacidolytic activities, or both.

\section{Influence of bifidobacteria on $\mathrm{H}_{2}$ excretion and butyric acid formation}

Hydrogen excretion was seven times higher in group A than in group $B$ (Table 5). No $\mathrm{H}_{2}$ was detected in group $\mathrm{A}+B$. inf., whereas it was unchanged in group $\mathrm{B}+B$. inf. Concerning the SCFA profiles, the relative proportion of butyric acid was four times higher in group A than in group B, but the concentration of this acid was not different between these two groups. In the presence of bifidobacteria, butyric acid disappeared in group $\mathrm{A}+B$. inf. and decreased at least by a factor 8 in group $\mathrm{B}+B$. inf. in both percentage and concentration. In group $C$, butyric acid concentration was similar to that of group $\mathrm{B}+B$. inf.

\section{Discussion}

These results confirm and extend the validity of the experimental model previously developed for $C$. butyricum with monobiotic quails [24]. A whole flora including three Clostridium spp. isolated from an NEC patient led to NEC-like caecal lesions in gnotobiotic quails similar to those observed in human infants. Conversely, a whole flora including bifidobacteria isolated from a healthy premature neonate was not able to produce NEC-like lesions in this animal model. Such a gnotobiotic model is very useful for a better understanding of the disease, whose exact pathogenesis remains unknown. It allows the preservation of the initial flora composition for long-term studies. It is reproducible, easy to perform and it rapidly produces NEC lesions without invasive methods. The development of lesions in quails requires a combination of several factors present in premature human infants, i.e., (i) a low endogenous intestinal lactase activity, (ii) the presence of lactose in the diet, (iii) the presence of lactose-fermenting anaerobes, and (iv) physiological stasis due to the specificity of the quail digestive tract anatomy. The lesions were quite similar to those observed in human infants suffering from NEC, with different states ranging from haemorrhagic caecitis to peritoneal pneumatosis. Quails display a host-mediated response, as in both the $C$. butyricum group and the complex flora group $28 \%$ and $44 \%$ of quails, respectively, were free of any caecal lesions with the same high bacterial level. These findings are consistent with those observed in premature infants, as Clostridium spp. 
Table 5. Influence of bifidobacteria on butyrate concentration and pattern in the caecal content and on in-vivo excretion of hydrogen in germ-free quails inoculated with various flora

\begin{tabular}{|c|c|c|c|c|c|c|}
\hline \multirow{2}{*}{$\begin{array}{l}\text { Group of quails } \\
\text { (n) }\end{array}$} & \multirow[b]{2}{*}{ Bifid. status } & \multirow[b]{2}{*}{ Outcome } & \multirow[b]{2}{*}{ Number of quails } & \multicolumn{2}{|c|}{ Butyrate } & \multirow[b]{2}{*}{$\begin{array}{l}\text { Hydrogen mean (SEM) } \\
\text { ppm }^{*}\end{array}$} \\
\hline & & & & molar ratio $(\%)$ & $\begin{array}{c}\text { mean (SEM) } \\
\text { concentration }(\mu \mathrm{mol} / \mathrm{g})\end{array}$ & \\
\hline \multirow[t]{2}{*}{ A (11) } & - & healthy & 3 & 21 & $1.2(0.4)$ & \multirow{2}{*}{$35(11)$} \\
\hline & & sick & 8 & 15 & $0.7(0.2)$ & \\
\hline \multirow[t]{2}{*}{ B (9) } & - & healthy & 3 & 5 & $1.6(0.1)$ & \multirow{2}{*}{$5.2(1.3)$} \\
\hline & & sick & 6 & 4 & $1.25(0.1)$ & \\
\hline C (8) & $+t^{\dagger}$ & healthy & 8 & 0.8 & $0.16(0.03)$ & $\cdots$ \\
\hline $\mathrm{A}+B$. inf. (11) & + & healthy & 11 & ND & ND & ND \\
\hline $\mathrm{B}+B$. inf. (8) & $+^{\ddagger}$ & healthy & 8 & 1.6 & $0.21(0.05)^{\S}$ & $6.8(1.7)$ \\
\hline
\end{tabular}

ND, not detected.

* Six quails from each group examined during a 4-h period in the respiratory chamber.

$\dagger{ }^{\dagger}$ See footnote to Table 2 .

$\S_{\mathrm{p}}<0.01$ versus quails in group B without bifidobacteria.

involved in NEC were found at high levels in stools from either sick or healthy premature infants [19].

Variations in intestinal bacteriology have been associated with a changing incidence of NEC [37]. The analysis of the two stool specimens did not reveal the presence of a great variety of micro-organisms, but their compositions were very different. This agrees with several previous observations that even 2 weeks after birth, the flora of premature infants do not always have the same composition [19] and the colonisation patterns differ from those of normal full-term infants $[8,10]$, in which a delayed bifidobacterial colonisation was noted $[9,10]$.

In the newborn infant who developed NEC, three Clostridium spp., C. butyricum, C. perfringens and C. difficile, were simultaneously isolated. In pre-term infants, colonisation by clostridia is observed in $c$. $10 \%$ of cases according to Blakey et al. [8] and a mixture of clostridia is quite unusual $[8,20,21,38]$. In a study dealing with isolation of clostridia from 77 faecal samples, Westra-Meijer et al. [12] isolated four species from one faecal sample and two species from three samples from another infant.

Modifications were observed in the levels of the different Clostridium strains in quail droppings as compared with the original human neonate faecal inoculum. In quails, the counts for $C$. difficile were quite similar and $C$. perfringens colonised quails well, unlike in the neonate, whereas $C$. butyricum failed to establish. Hoy et al. [39] demonstrated that the quantitative composition of the premature faecal microflora may vary from day to day and that quantitative changes occurred immediately before the clinical onset of NEC. Therefore, it cannot be concluded that bacterial changes observed in quails would not have appeared in the premature infant.

In this study, a marked protective role in vivo by bifidobacteria was demonstrated against the onset of NEC-like lesions. This may be related to the decrease of the $C$. butyricum population in group $\mathrm{A}+B$. inf. and to the disappearace of $C$. perfringens in group $\mathrm{B}+B$. inf. without unmodified $C$. difficile counts. Furthermore, $C$. butyricum was unable to colonise quails previously inoculated with the group $\mathrm{C}$ flora containing bifidobacteria. An association has been demonstrated previously between a high rate of colonisation by Clostridium spp., especially $C$. perfringens and an NEC outbreak $[14,15,18]$. The key role of $C$. butyricum in NEC development has been demonstrated previously with the two alactasic gnotobiotic models [23, 24, 40]. Neonatal colonisation by $C$. difficile is common even in pre-term infants and almost invariably asymptomatic, despite the detection in some cases of cytotoxin in stools [41-43]. Only in rare cases might $C$. difficile be involved in severe enterocolitis in neonates [44] and its possible role in NEC is controversial [45]. Despite the detection of $C$. difficile toxins in five infants with NEC, suggesting a role for this species [15], neither Chang and Areson [46] nor Bartlett et al. [47] found C. difficile cytotoxin in relation to NEC. From the results of the present study, $C$. perfringens and not $C$. difficile was shown to be responsible for the aetiology of the caecal lesions. The macroscopic examination of the caeca showed differences between sick animals in groups A and B. Haemorrhages, which predominated in group B, may be produced in relation to the action of the haemolytic C. perfringens toxins [18].

Bifidobacteria are thought to exert various beneficial effects on the host health including interactions with the colonic microflora. Different hypotheses have been proposed, among them the production of bacterial metabolites that have a direct inhibitory activity [48] or consequently lower the $\mathrm{pH}$, or both $[2,6,49]$, and the production of unknown antibacterial substances $[5,50]$.

Some authors observed an in-vitro inhibition by bifidobacteria of the growth of potential enteropathogens which was related to the production of lactic and acetic acids, thus lowering $\mathrm{pH}[6,51]$. Nevertheless, the inhibition can be observed even with $\mathrm{pH}-$ 
neutralised supernatant fluids from $B$. infantis cultures and the most active fractions (obtained after extraction) contained neither acetic acid nor lactic acid [5]. Similarly, in the present study, direct protection by bifidobacteria through lowering $\mathrm{pH}$ did not seem to be the mechanism of action in vivo as the caecal $\mathrm{pH}$ was not significantly modified.

Depending on the bacteriological status of the group, total SCFA amounts ranged from 4 to $30 \mu \mathrm{mol} / \mathrm{g}$ of content and were modified in response to bifidobacterial inoculation, in comparison with results reported by Bartram et al. [52], Hove et al. [53] and Okhusa et al. [54], but in their experiments increases in bifidobacteria were smaller than in this study.

The main effect in the present study was a dramatic decrease or a disappearance of butyric acid. The accumulation of large amounts of butyric acid produced from unabsorbed lactose was thought to be responsible for the increased caecal wall thickening in quails [24]. Then, a new step between colonic fermentation and its relevance to NEC is to involve butyric acid as a main factor in the onset of the disease. Butyric acid is considered to be essential for the integrity of the colonic epithelium [55]. It stimulates the proliferation of the epithelial colonic cells and is the major source of energy for the enterocytes. Nevertheless, it has been reported to be a cytotoxic agent in several isolated cell lines [56]. High concentrations of butyric acid were shown to exert toxic effects in animals leading to atony [57] and necrosis [58-60] of the intestinal epithelium. Butyric acid was related to the cytotoxic factor of $C$. butyricum strains involved in NEC [61]. In full-term babies, the butyric acid concentrations remain very low compared to premature infants $[2,62-65]$ and the SCFA pattern in breast-fed babies consists mainly of acetic acid. Besides $C$. butyricum and $C$. perfringens which are well known to form butyric acid from lactose, Carbonaro et al. [66] suggested that an increased ability for lactose fermentation for a Klebsiella strain and the ensuing production of organic acids may be a factor in the onset of NEC.

$\mathrm{H}_{2}$ has been incriminated in the development of mucosal pneumatosis $[67,68]$. In dixenic animals (group $\mathrm{A}+B$. inf.), $\mathrm{H}_{2}$ was not excreted. In heteroxenic quails in group $B$, bifidobacteria had no inhibiting effect on $\mathrm{H}_{2}$ production, which was low compared to production in monoxenic quails. In this case, $\mathrm{H}_{2}$ production should be attributed to $C$. difficile, as $C$. perfringens counts decreased markedly. Therefore, in the absence of butyric acid, $\mathrm{H}_{2}$ production has no deleterious effect.

This study is the first demonstration of a clear protective role for bifidobacteria against NEC and it is hypothesised that the inoculation of premature babies with selected Bifidobacterium strains could prevent the development of NEC via inhibition of the growth of potentially pathogenic bacteria such as $C$. butyricum, $C$. perfringens and $C$. difficile.

We are very grateful to Raffinerie Tirlemontoise, Tienen, Belgium, for supporting this study. Sincere thanks are expressed to Dr F. Gavini, Laboratoire de Génie des Procédés et Technologie Alimentaires, INRA, Villeneuve d'Ascq, France for providing the B.infantislongum strain and identifying $B$. pseudo-catenulatum strain, to $\mathrm{Dr}$ Taper, Unité des Sciences Pharmaceutiques, Université Catholique de Louvain, for the histological analyses and to Dr J. C. Borderon, Unité de Pathologie Infectieuse, Centre de Pédiatrie Gatien de Clocheville, Tours, France, for his advice.

\section{References}

1. Balmer SE, Wharton BA. Diet and faecal flora in the newborn: breast milk and infant formula. Arch Dis Child 1989; 64: $1672-1677$.

2. Bullen CL, Tearle PV, Willis AT. Bifidobacteria in the intestinal tract of infants: an in-vivo study. J Med Microbiol 1976; 9 325-333.

3. Stark PL, Lee A. The microbial ecology of the large bowel of breast-fed and formula-fed infants during the first year of life. $J$ Med Microbiol 1982; 15: 189-203.

4. Wharton BA, Balmer SE, Noy MF. Food and microbiological problems in the newborn: data and practice. Acta Paediatr Suppl 1994; 405: S29-S34.

5. Gibson GR, Wang X. Regulatory effects of bifidobacteria on the growth of other colonic bacteria. J Appl Bacteriol 1994; 77: $412-420$

6. Wang X, Gibson GR. Effects of the in vitro fermentation of oligofructose and inulin by bacteria growing in the human large intestine. J Appl Bacteriol 1993; 75: 373-380.

7. Gallaher DD, Stallings WH, Blessing LL, Busta FF, Brady LJ. Probiotics, cecal microflora, and aberrant crypts in the rat colon. J Nutr 1996; 126: 1362-1371.

8. Blakey JL, Lubitz L, Barnes GL, Bishop RF, Campbell NT, Gillam GL. Development of gut colonisation in pre-term neonates. J Med Microbiol 1982; 15: 519-529.

9. Hall MA, Cole CB, Smith SL, Fuller R, Rolles CJ. Factors influencing the presence of faecal lactobacilli in early infancy. Arch Dis Child 1990; 65: 185-188.

10. Sakata H, Yoshioka H, Fujita K. Development of the intestinal flora in very low birth weight infants compared to normal fullterm newborns. Eur J Pediatr 1985; 144: 186-190.

11. Neu J. Necrotizing enterocolitis: the search for a unifying pathogenic theory leading to prevention. Pediatr Clin North Am $1996 ; 43: 409-432$.

12. Westra-Meijer CMM, Degener JE, Dzoljic-Danilovic G, Michel MF, Mettau JW. Quantitative study of the aerobic and anaerobic faecal flora in neonatal necrotizing enterocolitis. Arch Dis Child 1983; 58: 523-528.

13. Speer ME, Taber LH, Yow MD, Rudolph AJ, Urteaga J, Waller S. Fulminant neonatal sepsis and necrotizing enterocolitis associated with a "nonenteropathogenic" strain of Escherichia coli. J Pediatr 1976; 89: 91-95.

14. Blakey $\mathrm{L}$, Lubitz L, Campbell NT, Gillam GL, Bishop RF, Barnes GL. Enteric colonization in sporadic neonatal necrotizing enterocolitis. $J$ Pediatr Gastroenterol Nutr 1985; 4: 591-595.

15. Cashore WJ, Peter G, Lauermann M, Stonestreet BS, Oh W. Clostridia colonization and clostridial toxin in neonatal necrotizing enterocolitis. $J$ Pediatr 1981; 98: 308-311.

16. Kliegman RM, Fanaroff AA, Izant R, Speck WT. Clostridia as pathogens in neonatal necrotizing enterocolitis. J Pediatr 1979; 95: $287-289$.

17. Kosloske AM, Ulrich JA, Hoffman H. Fulminant necrotising enterocolitis associated with clostridia. Lancet 1978; 2: 10141016.

18. Loc CM, Lanoche JCC, Paul G, Baudoin M. Infection à Clostridium perfringens et entérocolite ulcéro-nécrosante. Arch Fr Pediatr 1980; 37: 233-240.

19. Gothefors L, Blenkharn I. Clostridium butyricum and necrotising enterocolitis, Lancet 1978; 1: 52-53.

20. Howard FM, Flynn DM, Bradley JM, Noone P, Szawatkowski 
M. Outbreak of necrotising enterocolitis caused by Clostridium butyricum. Lancet 1977; 2: 1099-1102.

21. Laverdière M, Robert A, Chicoine R, Salet D, Rosenfeld R. Clostridia in necrotising enterocolitis. Lancet 1978; 2: 377.

22. Lawrence G, Bates J, Gaul A. Pathogenesis of neonatal necrotising enterocolitis. Lancet 1982; 1: 137-139.

23. Popoff MR, Szylit O, Ravisse P, Dabard J, Ohayon H. Experimental cecitis in gnotoxenic chickens monoassociated with Clostridium butyricum strains isolated from patients with neonatal necrotizing enterocolitis. Infect Immun 1985; 47: 697-703.

24. Bousseboua H, Le Coz Y, Dabard J et al. Experimental cecitis in gnotobiotic quails monoassociated with Clostridium butyricum strains isolated from patients with neonatal necrotizing enterocolitis and from healthy newborns. Infect Immun 1989; 57: $932-936$.

25. Book LS, Herbst JJ, Jung AL. Carbohydrate malabsorption in necrotizing enterocolitis. Pediatrics 1976; 65: 201-204.

26. Clark DA, Miller MJS. Intraluminal pathogenesis of necrotizing enterocolitis. J Pediatr 1990; 117: S64-S67.

27. Clark DA, Thompson JE, Weiner LB, McMillan JA, Schneider AJ, Rokahr JE. Necrotizing enterocolitis: intraluminal biochemistry in human neonates and a rabbit model. Pediatr Res 1985; 19: 919-921.

28. Engel RR, Virning NL, Hunt CE, Levitt MD. Origin of mural gas in necrotizing enterocolitis. Pediatr Res 1973; 7: 292 (abstract).

29. Cummings JH. Short chain fatty acids in the human colon. Gut 1981; 22: 763-779.

30. Lucas A, Cole TJ. Breast milk and neonatal necrotizing enterocolitis. Lancet 1990; 2: 1519-1523.

31. Reyniers JA, Sacksteder MR. Raising Japanese quail under germfree and conventional conditions and their use in cancer research. J Natl Cancer Inst 1960; 24: 1405-1421.

32. Le Coz Y, Szylit O, Ducluzeau R. Mise au point d'isolateurs souples destinés à des études nutritionnelles sur poulets axéniques et gnotoxéniques. Sci Technol Anim Lab 1977; 2: 27-33.

33. de Vos N, Mevissen-Verhage E, van Amerongen WH, Marcelis J. A new selective medium for the culture of clostridia from human faeces. Eur J Clin Microbiol 1982; 1: 267-271.

34. Popoff MR. Selective medium for isolation of Clostridium butyricum from human feces. J Clin Microbiol 1984; 20: 417-420.

35. Holdeman LV, Moore WEC, Cato EP. Anaerobe laboratory manual, 4th edn. Blacksburg, VA, Virginia Polytechnic Institute and State University. 1977.

36. Ottenstein DM, Bartley DA. Separation of free acids $\mathrm{C}_{2}-\mathrm{C}_{5}$ in dilute aqueous solution column technology. $J$ Chromatogr Sci 1971; 9: 673-681.

37. Bell MJ, Feigin RD, Ternberg JL. Changes in the incidence of necrotizing enterocolitis associated with variation of the gastrointestinal microflora in neonates. Am J Surg 1979; 138: 629-631.

38. Kelsey MC, Vince AJ. Clostridia in neonatal faeces. Lancet 1979; 2: 100 .

39. Hoy C, Millar MR, MacKay P, Godwin PGR, Langdale V, Levene MI. Quantitative changes in faecal microflora preceding necrotising enterocolitis in premature neonates. Arch Dis Child 1990; 65 (10 spec. no.): $1057-1059$.

40. Bousseboua H, Le Coz Y, Szylit O. Relation between the fermentation products of lactose and experimental cecitis in monoxenic quails. Microbiol Ther 1996; 24: 155-160.

41. Bolton RP, Tait SK, Dear PRF, Losowsky MS. Asymptomatic neonatal colonisation by Clostridium difficile. Arch Dis Child 1984; 59: 466-472.

42. Cardines R, Luzzi I, Menichella G, Virgili Q, Mastrantonio P. Clostridium difficile in preterm neonate. Microbiologica 1988; 11: $259-261$.

43. el-Mohandes AE, Keiser JF, Refat M, Jackson BJ. Prevalence and toxigenicity of Clostridium difficile isolates in fecal microflora of preterm infants in the intensive care nursery. Biol Neonate 1993; 63: 225-229.

44. Price EH, Borriello SP, Ward H, Brereton R, Risdon RA,
Tabaqchali S. Clostridium difficile and severe enterocolitis in three infants. In: Boriello SP (ed) Clinical and molecular aspects of anaerobes. Petersfield, Wrightson Biomedical Publishing 1990: 75-79.

45. Han VKM, Sayed H, Chance GW, Brabyn DG, Shaheed WA An outbreak of Clostridium difficile necrotizing enterocolitis: a case for oral vancomycin therapy? Pediatrics 1983; 71: 935-941.

46. Chang T-W, Areson P. Neonatal necrotizing enterocolitis: absence of enteric bacterial toxins. $N$ Engl $J$ Med 1978; 299 : 424.

47. Bartlett JG, Moon N, Chang TW, Taylor N, Onderdonk AB Role of Clostridium difficile in antibiotic-associated pseudomembranous colitis. Gastroenterology 1978; 75: 778-782.

48. Rolfe RD. Role of volatile fatty acids in colonization resistance to Clostridium difficile. Infect Immun 1984; 45: 185-191.

49. Bullen CL, Tearle PV. Bifidobacteria in the intestinal tract of infants: an in vitro study. J Med Microbiol 1976; 9 335-344.

50. Anand SK, Srinivasan RA, Rao LK. Antibacterial activity associated with Bifidobacterium bifidum - II. Cultured Dairy Products Journal 1985; 2: 21-23.

51. Tamura Z. Nutriology of bifidobacteria. Bifidobacteria Microflora 1983; 2: 3-16.

52. Bartram HP, Scheppach W, Gerlach S, Ruckdeschel G, Kelber E, Kasper H. Does yogurt enriched with Bifidobacterium longum affect colonic microbiology and fecal metabolites in healthy subjects? Am J Clin Nutr 1994; 59: 428-432.

53. Hove H, Nordgaard-Andersen I, Mortensen PB. Effect of lactic acid bacteria on the intestinal production of lactate and shortchain fatty acids, and the absorption of lactose. Am J Clin Nutr 1994; 59: 74-79.

54. Okhusa T, Ozaki Y, Sato C, Mikuni K, Ikeda H. Long-term ingestion of lactosucrose increases Bifidobacterium $\mathrm{sp}$. in human fecal flora. Digestion 1995; 56: 415-420.

55. Roediger WEW. Role of anaerobic bacteria in the metabolic welfare of the colonic mucosa in man. Gut 1980; 21: 793-798.

56. Kruh J. Effects of sodium butyrate, a new pharmacological agent, on cells in culture. Mol Cell Biochem 1982; 42: 65-82.

57. Svendsen P. The effect of volatile fatty acids and lactic acid on rumen motility in sheep. Nord Vet Med 1973; 25: 226-231.

58. Galfi P, Neogrady S, Kutas F, Veresegyhazy T. Keratinization of cultured ruminal epithelial cells treated with butyrate and lactate. Zentralbl Veterinarmed A 1983; 30: 775-781.

59. Galfi P, Neogrady S, Veresegyhazy T, Kutas F. Demonstration of keratinizing effect of n-butyrate on day-old chicken crop epithelium. Zentralbl Veterinarmed A 1985; 32: 146-150.

60. Sakata T, Tamate $H$. Rumen epithelial cell proliferation accelerated by rapid increase in intraruminal butyrate. $J$ Dairy Sci 1978; 61: 1109-1113.

61. Popoff MR, Jolivet-Reynaud C, Carlier JP. Cytotoxic activity of Clostridium butyricum supernatants induced by butyrate. FEMS Microbiol Lett 1987; 43: 95-100.

62. Edwards CA, Parrett AM, Balmer SE, Wharton BA. Faecal short chain fatty acids in breast-fed and formula-fed babies. Acta Paediatr 1994; 83: 459-462.

63. Midtvedt AC, Midtvedt T. Production of short chain fatty acids by the intestinal microflora during the first 2 years of human life. J Pediatr Gastroenterol Nutr 1992; 15: 395-403.

64. Siigur U, Ormisson A, Tamm A. Faecal short-chain fatty acids in breast-fed and bottle-fed infants. Acta Paediatr 1993; 82: 536-538.

65. Rasmussen HS, Holtug K, Ynggard C, Mortensen PB. Faecal concentrations and production rates of short chain fatty acids in normal neonates. Acta Paediatr Scand 1988; 77: 365-368.

66. Carbonaro CA, Clark DA, Elseviers D. A bacterial pathogenicity determinant associated with necrotizing enterocolitis. Microb Pathog 1988; 5: 427-436.

67. Cheu HW, Brown DR, Rowe MI. Breath hydrogen excretion as a screening test for the early diagnosis of necrotizing enterocolitis. Am J Dis Child 1989; 143: 156-159.

68. Garstin WI, Boston VE. Assessment of hindgut function in premature newborns. J Pediatr Surg 1987; 22: 353-355. 